\title{
Anterior Jugular Vein
}

National Cancer Institute

\section{Source}

National Cancer Institute. Anterior Jugular Vein. NCI Thesaurus. Code C32094.

A vein arising near the hyoid bone from several veins from the submaxillary region. It terminates in the external jugular vein. 